\title{
The changing atmospheric water cycle in Polar Regions in a warmer climate
}

\author{
By LENNART BENGTSSON ${ }^{1,2 *}$, KEVIN I. HODGES ${ }^{1}$, SYMEON KOUMOUTSARIS ${ }^{2}$, \\ M ATTHIAS ZAHN ${ }^{1}$ and NOEL KEENLY SIDE ${ }^{3}, \quad{ }^{1}$ NERC Centre for Earth Observation (NCEO), \\ University of Reading, Whiteknights, PO Box 238, Reading, RG6 6AL, UK $;{ }^{2}$ International Space Science Institute \\ (ISSI), Hallerstrasse 6, CH-3012 Bern, Switzerland; ${ }^{3}$ Leibniz Institute of Marine Sciences, IFM-GEOMAR, \\ Düsternbrooker Weg 20, D-24105 Kiel, Germany.
}

(Manuscript received 5 January 2011; in final form 20 June 2011)

\begin{abstract}
We have examined the atmospheric water cycle of both Polar Regions, polewards of $60^{\circ} \mathrm{N}$ and $60^{\circ} \mathrm{S}$, using the ERAInterim reanalysis and high-resolution simulations with the ECHAM5 model for both the present and future climate based on the IPCC, A1B scenario.

The annual precipitation in ERA-Interim amounts to $\sim 17000 \mathrm{~km}^{3}$ and is more or less the same in the Arctic and the Antarctic, but it is composed differently. In the Arctic the annual evaporation is $\sim 8000 \mathrm{~km}^{3}$ but $\sim 3000 \mathrm{~km}^{3}$ less in the Antarctica where the net horizontal transport is correspondingly larger. The net water transport of the model is more intense than in ERA-Interim, in the Arctic the difference is 2.5\% and in the Antarctic it is 6.2\%. Precipitation and net horizontal transport in the Arctic has a maximum in August and September. Evaporation peaks in June and July. The seasonal cycle is similar in Antarctica with the highest precipitation in the austral autumn. The largest net transport occurs at the end of the major extra-tropical storm tracks in the Northern Hemisphere such as the eastern Pacific and eastern north Atlantic.

The variability of the model is virtually identical to that of the re-analysis and there are no changes in variability between the present climate and the climate at the end of the 21 st century when normalized with the higher level of moisture. The changes from year to year are substantial with the 20- and 30-year records being generally too short to identify robust trends in the hydrological cycle.

In the A1B climate scenario the strength of the water cycle increases by some $25 \%$ in the Arctic and by $19 \%$ in the Antarctica, as measured by annual precipitation. The increase in the net horizontal transport is $29 \%$ and $22 \%$, respectively, and the increase in evaporation correspondingly less. The net transport follows closely the Clausius-Clapeyron relation. There is a minor change in the annual cycle of the Arctic atmospheric water cycle with the maximum transport and precipitation occurring later in the year.

There is a small imbalance of some $4-6 \%$ between the net transport and precipitation minus evaporation. We suggest that this is mainly due to the fact that the transport is calculated from instantaneous six hourly data while precipitation and evaporation is accumulated over a 6-h period. The residual difference is proportionally similar for all experiments and hardly varies from year to year.
\end{abstract}

\section{Introduction}

Observational studies as well as results from numerical models show that water vapour in the atmosphere closely follows the temperature in agreement with the Clausius-Clapeyron (CC) relation. There is no tendency for the atmosphere to conserve relative humidity per se but rather that the moisture content of any three-dimensional air trajectory depends on the temperature at the last incident of condensation (Pierrehumbert et al., 2007).

\footnotetext{
* Corresponding author.

e-mail: lennart.bengtsson@zmaw.de

DOI: 10.1111/j.1600-0870.2011.00534.x
}

This means that an increase in temperature by $1{ }^{\circ} \mathrm{C}$ in the lower troposphere implies an increase in the water vapour by $6-7 \%$. However, the corresponding increase in the hydrological cycle, in terms of the global mean evaporation and precipitation, as obtained from model integrations, is limited to some 1-2\% (Held and Soden, 2006). There is no physical reason why the global precipitation and atmospheric moisture should change by the same amount but rather they may change differently. Evaporation is a consequence of the radiation imbalance at the surface as well as being influenced by the surface winds, stability of the boundary layer and the absorption of short wave radiation in the atmosphere (Takahashi, 2009). 
However, it is not currently possible to verify such changes from observational records of precipitation, mainly due to insufficient global sampling. Validation of the hydrological cycle for specific regions can be highly misleading as precipitation will increase rapidly in areas of convergence and correspondingly decrease in areas of divergence. This is also a consequence of the $\mathrm{CC}$ relation. The fact that the increase in water vapour follows the $\mathrm{CC}$ relation has a number of other important consequences, including the poleward transport of water vapour and the pattern of precipitation minus evaporation $(P-E)$. The $P-E$ gradient increases in proportion to the lower tropospheric water vapour, (Held and Soden, 2006) as the net transport of water vapour scales with the $\mathrm{CC}$ relation. An implication of this is that wet regions get wetter and dry regions get drier. This result is of key importance for an understanding of how future patterns of precipitation might change in a warmer climate. This includes an increase in precipitation in the Inter-Tropical Convergence Zone and in the middle and high latitude storm tracks. It also means less precipitation in most parts of the subtropics and an increase in transport of water vapour into the Polar Regions that affects the regional water balance there.

The Polar Regions are areas with a net convergence of water vapour that is important for the net mass balance of the land ice and the high latitude glaciers (e.g. Lettau, 1969; Bromwich and Wang, 2008). Calculations of the size of this transport have been carried out by many researchers over a long period of time, first from upper air observations and later from operational analyses and finally during recent decades from reanalyses. A serious limitation has been the lack of regular observations in the Polar Regions, however following the Global Weather Experiment in 1979 the situation has significantly improved, most remarkably in the SH. Examples of studies during the last two decades are for the Arctic: Cullather et al. (2000), Rogers et al. (2001), Bromwich et al. (2002), Serreze et al. (2003, 2006), Bromwich et al. (2007), Bromwich and Wang (2008), Jakobson and Vihma (2010), and for the Antarctic: Lettau (1969), Giovinetto et al. (1992), Giovinetto et al. (1997), Genthon and Krinner (1998), Bromwich and Wang (2008), Tietäväinen and Vihma (2008), Nicholas and Bromwich (2011). These studies have reported a net convergence of water vapour in the Polar region in broad agreement with observational estimates.

As has been shown by Held and Soden (2006), water vapour in the atmosphere scales with the $\mathrm{CC}$ relation and so does the convergence of water vapour. This implies an increase by about $7 \%$ for each degree of warming. Kattsov et al. (2007) have examined the simulations of the Arctic freshwater budget by the IPCC AR4 Global Climate Models and show that there is a major increase in both precipitation and in precipitation-evaporation $(P-E)$ towards the end of the 21 st century $(21 \mathrm{C})$.

In this paper, the transport of water vapour into the Arctic, $\left(60^{\circ}-90^{\circ} \mathrm{N}\right)$ and Antarctic $\left(60^{\circ}-90^{\circ} \mathrm{S}\right)$ regions is explored, and how this may change in a warmer climate. We use the notation Arctic and Antarctic to specifically refer to these regions. The purpose of this study is to explore the atmospheric water budget in some detail using a climate model where the atmospheric component has a high horizontal resolution of T213 triangular spectral truncation $(640 \times 320$ Gaussian grid $)$.

The following scientific questions are addressed:

(1) How large is the net transport of water vapour into the Polar Regions and how does it vary annually and by season? How large are the natural variations?

(2) How does the net transport vary regionally?

(3) How well can a high resolution GCM simulate the net transport?

(4) How might the net transport of water vapour change in a warmer climate?

A full description of the data and analysis methodology used is given in Section 2. In Section 3 results are discussed for a budget calculation of the Polar Regions using atmospheric data for winds and water vapour from a recent relatively high resolution re-analysis. In Section 4, we undertake a similar budget calculation using data from a recent global high-resolution climate experiment. In this case the experiment covers two 30-year periods, one representing the climate at the end of the 20th century (20C) and another representing the climate at the end the $21 \mathrm{C}$. Section 5 discusses the results with some general considerations for future work.

\section{Data and methodology}

The data used in this study are from a recent reanalysis, namely the European Centre for Medium-Range Weather Forecasts (ECMWF) ERA-Interim (Simmons et al., 2007; Dee and Uppala, 2009; Dee et al., 2011), for the period 1989-2009, and from a recent global high-resolution climate experiment (Bengtsson et al., 2007, 2009). The ERA-Interim is produced with a modern Numerical Weather Prediction system consisting of a comprehensive model of the atmosphere, IFS cycle $31 \mathrm{r} 1 / 2$, with the dynamical component formulated in spectral space at horizontal resolution of T255 and with 60 vertical hybrid levels. An atmospheric reanalysis combines the inhomogeneous historical observations of the atmosphere with the forecast model in a dynamically consistent way using data assimilation. For ERA-Interim this is done using a 12-h cycling four-dimensional variational (4D-Var.) method.

The result of this is a set of analyses every $6 \mathrm{~h}$ in which the archived fields are homogeneous in space and time. However, the fact that the observing system has changed significantly over time can introduce spurious 'jumps' into long-term reanalyses (Bengtsson et al., 2004). However, as the ERA-Interim is only available for the period after the introduction of the main satellite observing systems this is less of an issue. In fact modern NWP systems are better able to use the satellite observations than older systems which together with improvements in the quality of these observations has lead to significant improvements in the production of analyses and hence predictability (Simmons et al., 2007). 
The data from the reanalysis used in this study consist of specific humidity and winds on the model levels and the surface pressure every $6 \mathrm{~h}$, which allows the transport to be computed on model levels and accurately integrated in the vertical over the atmospheric column. In fact we restrict this to the troposphere, below $200 \mathrm{hPa}$, as the contribution of moisture from the stratosphere is insignificant. We undertake the calculations in model coordinates to avoid problems over the orography. This is especially important for water vapour because the majority of the transport occurs in the lower part of the troposphere, some $50 \%$ of the transport is below $800 \mathrm{hPa}$ and the peak of the transport is found in the planetary boundary layer (see later). It is hard to believe that calculations on pressure surfaces can avoid problems with accuracy over orographic regions, in particular at the latitudes previously used for these types of calculations. For example, several previous studies have used $70^{\circ} \mathrm{N}$ and $70^{\circ} \mathrm{S}$ as a latitude to define the Polar Region. Using $70^{\circ} \mathrm{S}$ for the $\mathrm{SH}$ has the disadvantage that a third of the latitude circle passes over land on East Antarctica making it difficult to obtain representative and reliable transport calculations as well as not incorporating the full size of the Antarctic continent.

In addition, to explore the moisture budget the precipitation and evaporation every $6 \mathrm{~h}$ are used. These are not analysed and must be obtained from the forecast as accumulated values. As the analysis cycle is every $12 \mathrm{~h}$ the six hourly precipitation and evaporation are determined by differencing the accumulated values from the forecasts initialised at 00 and $12 \mathrm{~h}$ at lead times of 18, 24 and $30 \mathrm{~h}$. This has the benefit of being far enough away from the analysis to exclude the influence of the spin-up. However, there is clearly an inconsistency in using instantaneous data for the transport and accumulated values for the precipitation and evaporation so we might expect some discrepancy in the budget calculations. Calculation has shown that contributions to this discrepancy from ignoring the stratosphere and the region between the lowest model level and the surface are less than $1 \%$.

The same data is used from the climate model simulations. The atmospheric climate model used is the Max-Planck Institute for Meteorology, ECHAM5 (Roeckner et al., 2006) integrated for two 32 year periods representative of the end of the $20 \mathrm{C}$ (1959-1990) and the end of the 21C (2069-2100) based on the Intergovernmental Panel on Climate Change (IPCC) 4th assessment SRES A1B scenario (Nakicenovic et al., 2000). The simulations are of the time slice type forced with Sea Surface Temperatures (SST) and sea ice boundary data from a coupled climate simulation with the same model at $\mathrm{T} 63$ resolution. The simulations are produced at a spectral resolution of T213 with 31 hybrid sigma vertical levels. These are the same simulations as used in the studies of Bengtsson et al., (2007, 2009) of tropical and extra-tropical cyclones, respectively.

There are two possible methods to compute the 'wall' transport into a particular region, which are equivalent. The first is to compute the area integral over some region of the divergence of the vertically integrated moisture flux and the second is the line integral around the region of the vertically integrated moisture flux across the region boundary. The two are equivalent by the Gauss divergence theorem, for an area $A$ bounded by the curve $L$ we have

$$
\begin{aligned}
\text { Moisture Flux } & =\frac{1}{g} \int_{A} \nabla \cdot \int_{p_{\mathrm{o}}}^{p_{1}} \underline{V} q \mathrm{~d} p \mathrm{~d} a \\
& =\frac{1}{g} \oint_{L} \int_{P_{o}}^{P_{1}} V_{n} q \mathrm{~d} p \mathrm{~d} l,
\end{aligned}
$$

where $V_{n}$ is the normal velocity to $L, q$ is specific humidity, $\underline{V}$ are the vector winds and $g$ is the acceleration due to gravity. The vertical integration is between the pressures on the lowest model level and the chosen highest level. Note, that for simple domains such as the polar cap regions, bounded by fixed lines of latitude, the normal velocity is simply the meridional wind. However, the line integral approach can also be easily applied to more general spherical cap regions with the normal velocity obtained by using the same approach used to compute radial and tangential winds for storm centred composites (Bengtsson et al., 2007). Also note, that we will use the convention that positive values of the moisture flux implies flow into the region because we believe this to be the more natural convention although this is contrary to similar studies for the transport into the polar regions.

There are pros and cons to both approaches; the divergence approach is easier to apply to irregular regions and for different regions as the divergence only needs to be computed once on the data grid. The line integral approach is more useful if we want to see where the transport occurs across the boundary by looking at the fluxes before applying the line integration and also the relative proportions of inflow and outflow. The vertical integration with respect to pressure is performed over the model levels using a trapezoidal quadrature with the pressure at each level being obtained from the surface pressure and the model levels. The regions chosen for this study are those polewards of $60^{\circ} \mathrm{N}$ and $60^{\circ} \mathrm{S}$, which has the benefit that both Greenland and the Antarctic continent are fully incorporated. The fact that six hourly data is used for all calculations, is considered to be sufficient to include the effects from rapidly moving and changing synoptic weather systems. The six hourly flux data is averaged to produce monthly and annual means.

\section{The water balance of the Polar Regions from reanalyses}

In this section, the transport and moisture budget are discussed for the Arctic $\left(60^{\circ}-90^{\circ} \mathrm{N}\right)$ and Antarctic $\left(60^{\circ}-90^{\circ} \mathrm{S}\right)$ regions computed from the ERA-Interim data.

\section{The Arctic region}

A summary of the water cycle in the Arctic region is given in Table 1. The annual mean Arctic precipitation for the period 1989-2009 obtained from the ERA-Interim reanalysis amounts 
Table 1. Mean annual values for the atmospheric water cycle in the region $60^{\circ}-90^{\circ} \mathrm{N}$ in units of $\mathrm{km}^{3} \mathrm{yr}^{-1}$.

\begin{tabular}{lrrrr}
\hline & ERA-Int. & ECHAM5 & ECHAM5 & Change \\
& $1989-2009$ & 1959-1990 & 2069-2100 & \\
\hline Precip. $(P)$ & 17408 & 17630 & 21975 & $+25 \%$ \\
Evap. $(E)$ & 8073 & 7933 & 9516 & $+20 \%$ \\
$P-E$ & 9335 & 9698 & 12459 & $+28 \%$ \\
Transp. $(T)$ & 8830 & 9048 & 11688 & $+29 \%$ \\
$(P-E)-T$ & 505 & 649 & 771 & \\
\hline
\end{tabular}

Note: Transport indicates the net transport of water vapour across $60^{\circ} \mathrm{N}$.

to $17408 \mathrm{~km}^{3}$ and the evaporation to $8073 \mathrm{~km}^{3}$. These data agree broadly with other estimates (e.g. Serreze et al., 2006, Rawlins et al., 2010). The transport of water vapour into the Arctic region is slightly higher than the evaporation or 8830 $\mathrm{km}^{3}$. There is no complete balance between transport, $T$ and $P-E$ but a small residual difference of $505 \mathrm{~km}^{3}, T$ being slightly smaller than $P-E$. This amount is more or less the same from year to year and also shows up in the model experiments as well, but is proportionally slightly larger (see later). We suggest that this is most likely due to the different ways that $T$ and $P-E$ are calculated. $T$ is calculated from instantaneous wind and moisture data at every $6 \mathrm{~h}$ but as explained in Section $2, P-E$ is accumulated for every time step and summed up in 6-h intervals.

We have further examined the relation between transport, $T$, precipitation, $P$ and evaporation, $E$ month by month. It is found that changes are consistent with the increased storage of moisture in the atmosphere because of temperature variations. Calculation shows that the atmospheric mean storage of water in the Arctic in the winter months is around $150 \mathrm{~km}^{3}$ increasing to a maximum of ca. $450 \mathrm{~km}^{3}$ in July. This variation in moisture is consistent with the seasonal change in temperature of the lower troposphere $(850-700 \mathrm{hPa})$ and a relative humidity of some $60 \%$.

The maximum transport occurs during September with 950 $\mathrm{km}^{3}$ and the smallest in February with $606 \mathrm{~km}^{3}$. Generally there are only minor variations from February through June and then a sharp transfer to markedly stronger transport during July that continues through late summer and autumn (Fig. 1).

The regions where the transport occurs, with respect to longitude, can be examined by omitting the line integral from the right hand side of eq. (1), this is shown in Fig. 2 for the four seasons. The maximum net transport occurs in the area between Iceland and Norway (longitudinal section $45^{\circ} \mathrm{W}-5^{\circ} \mathrm{E}$ ) and this dominates the transport into the Arctic for all seasons with a maximum during winter. A second maximum is found over the eastern $\mathrm{Pa}$ cific with a sharp winter maximum around $145^{\circ} \mathrm{W}$ and a summer maximum around $160^{\circ} \mathrm{W}$. The summer maximum is related to the band of cyclone activity from Japan north-eastwards over the Pacific. The Atlantic and Pacific region dominate the transport. For other latitudes the transport is minor and areas of negative net transport (that is moisture transport out of the Arctic), such

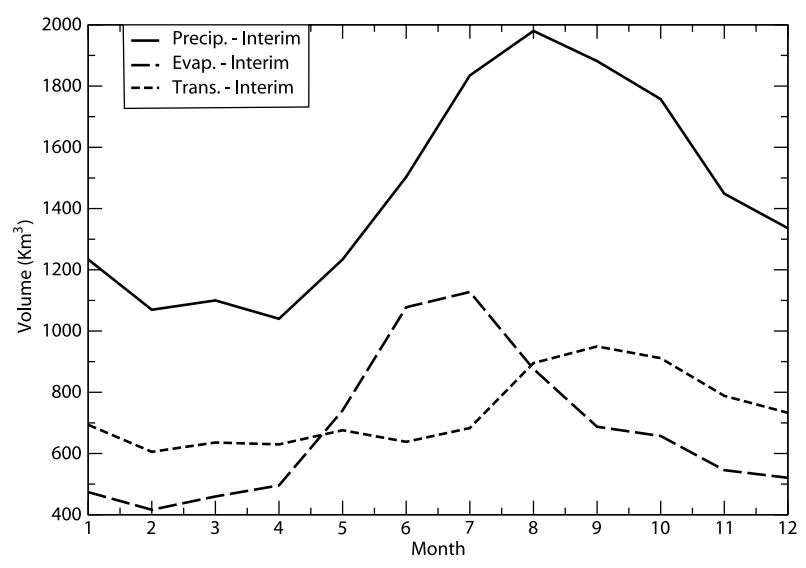

Fig. 1. Seasonal cycle of precipitation (solid), evaporation (long dashed) and transport (short dashed) into the Arctic region $\left(60^{\circ}-90^{\circ} \mathrm{N}\right)$ for ERA-Interim. Units are $\mathrm{km}^{3}$.

as over the central US can also be seen. The vertical profile of the transport can also be explored, this is shown in Fig. 3 for the four seasons. This shows that the transport in the lower troposphere dominates with the profile rapidly decreasing towards zero as the tropopause is approached. Figure 3 also shows that there is some seasonal variability in the vertical distribution. During the winter the peak transport is found around $960 \mathrm{hPa}$, but is slightly higher up in the other seasons.

There are considerable inter-annual variations in the Arctic hydrological cycle, including the horizontal transport. There is also a direct relation between Arctic annual precipitation and the lateral transport into the region, with an annual correlation of 0.88 . The variation in the inter-annual moisture transport is illustrated in Fig. 4 where the annual transport is shown in terms of longitude for the years 1989 (high net transport) and 2001 (low net transport). The annual transport in 1989 is $9752 \mathrm{~km}^{3}$ and $8451 \mathrm{~km}^{3}$ in 2001 , this is a difference of $15 \%$. The large transport in 1989 compared to 2001 in the Norwegian Sea stands out. A contributing factor to the large difference in moisture transport between the $2 \mathrm{yr}$ might be the stronger zonal temperature gradient around $60^{\circ} \mathrm{N}$ in the lower troposphere in 1989 supporting increased baroclinicity with more active transient extra-tropical cyclones.

In the observational record there is an global mean warming trend in the lower troposphere of about $0.15-0.20^{\circ} \mathrm{C} / \mathrm{dec}$ ade between 1989 and 2009 (calculated from ERA-Interim) but there is no discernible trend in the transport of moisture into the Arctic region from the data calculated for the ERA-Interim. This suggests that the natural changes dominate and the period is too short for a robust trend to be identified.

\section{The Antarctic region}

The water cycle in the Antarctic region is summarised in Table 2. In the reanalysis the annual mean Antarctic precipitation 


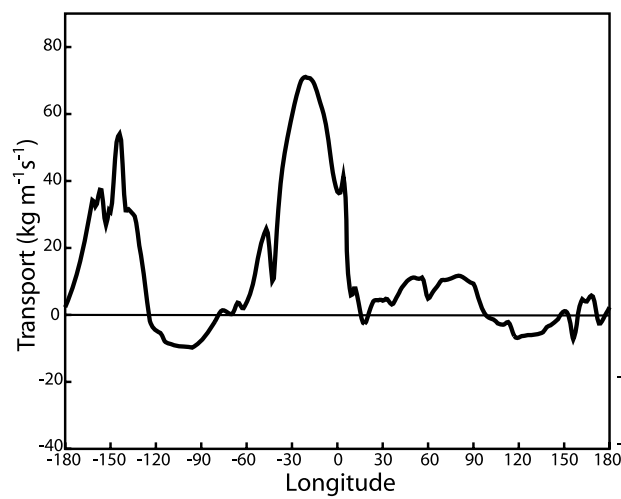

(a) DJF

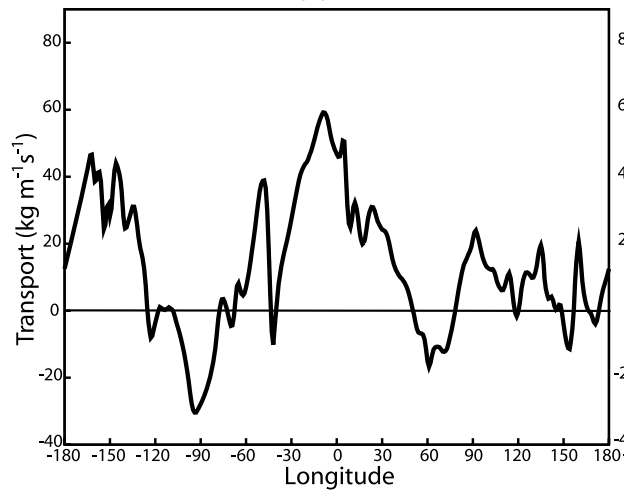

(c) JJA

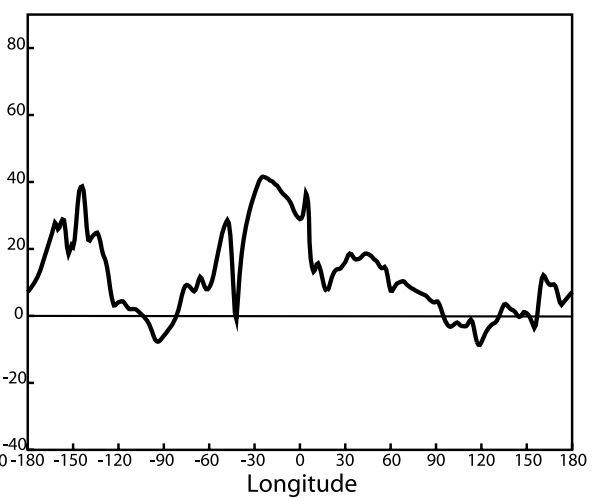

(b) MAM

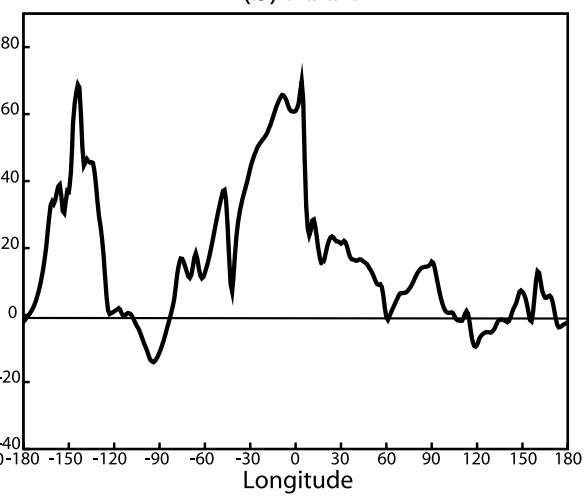

(d) SON

Fig. 2. Mean transport across $60^{\circ} \mathrm{N}$ for ERA-Interim for (a) Winter (DJF), (b) Spring (MAM), (c) Summer (JJA) and (d) Autumn (SON). Units are $\mathrm{kg} \mathrm{m}^{-1} \mathrm{~s}-1$.

is $16903 \mathrm{~km}^{3}$, a similar order of magnitude as in the Arctic, the evaporation is considerably smaller at $5140 \mathrm{~km}^{3}$. Consequently the transport of water vapour into the region across $60^{\circ} \mathrm{S}$ is some $30 \%$ larger than in the Arctic and amounts to $11322 \mathrm{~km}^{3}$. The residual difference between $P-E$ and the transport is $442 \mathrm{~km}^{3}$, as was found for the Arctic region, the transport being smaller than $P-E$. Because of the lower temperature the amount of water vapour in the atmosphere of the Antarctic region is significantly less compared to the Arctic region. The minimum value is found in September with $100 \mathrm{~km}^{3}$ and maximum in December of $180 \mathrm{~km}^{3}$.

The monthly values of precipitation, evaporation and transport are shown in Fig. 5. This shows that the maximum transport and the maximum precipitation occurs in March through May, but except for a marked minimum in December and January, the monthly values vary rather little between March and October. As in the Arctic the transport of moisture into Antarctica is slightly smaller than $P-E$ with about the same percentage confirming that this is due to differences in the calculation.

Figure 6 shows the transport across $60^{\circ} \mathrm{S}$ into the Antarctic region. The maximum transport for all seasons occurs in the western Indian Ocean sector $30^{\circ} \mathrm{E}-80^{\circ} \mathrm{E}$. This is a region, which has strong storm track activity throughout the year (Hoskins and Hodges, 2005). Other regions also show enhanced transport but vary seasonally, for example, there is another sharp peak around $100^{\circ} \mathrm{W}$ in the Pacific in DJF which is reduced in the other seasons. The Australian and West Pacific region experiences significant seasonal changes in the storm tracks associated with the development of the split jet through this region which likely explains the larger seasonal variability of the transport in this region. The general impression is that the pattern is smoothed out, compared to the $\mathrm{NH}$, and varies more with the season, and with positive transports at practically all longitudes. Figure 7 shows the vertical profile of the transport for each season. Compared to the NH there is much less seasonal variation, with the smallest transport occurring in the SH summer (DJF). Maximum transport occurs around $975 \mathrm{hPa}$.

\section{Atmospheric water cycle in Polar Regions in a warmer climate}

The changes in the hydrological cycle between 20C and 21C are significant and are summarised in Tables 1 and 2.

\section{The Arctic region}

The model simulation for $20 \mathrm{C}$ reproduces the atmospheric water cycle quite accurately with the annual mean values for 


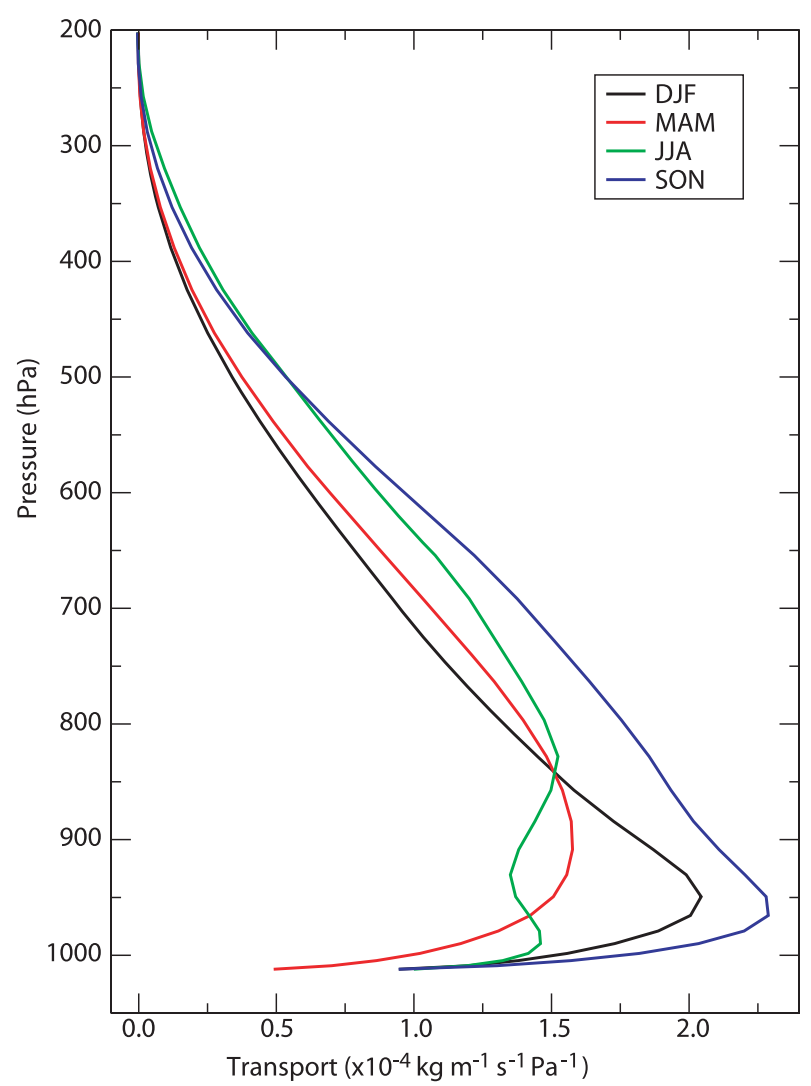

Fig. 3. Northern hemisphere mean vertical profile of the moisture transport across $600 \mathrm{~N}$. Units are $\times 10^{-4} \mathrm{~kg} \mathrm{~m}^{-1} \mathrm{~s}^{-1} \mathrm{~Pa}^{-1}$.

precipitation, evaporation and transport differing from ERAInterim by $+1.3,-1.7$ and $+2.5 \%$, respectively (see Table 1 ). The corresponding monthly values of $(P-E)-T$ (not shown) are larger, but for practically all months are within $10 \%$. The slightly
Table 2. Same as Table 1 but for $60^{\circ}-90^{\circ} \mathrm{S}$.

\begin{tabular}{lrrrr}
\hline & $\begin{array}{c}\text { ERA-Int. } \\
1989-2009\end{array}$ & $\begin{array}{c}\text { ECHAM5 } \\
1959-1990\end{array}$ & $\begin{array}{c}\text { ECHAM5 } \\
2069-2100\end{array}$ & Change \\
\hline Precip. $(P)$ & 16903 & 18509 & 22103 & $+19 \%$ \\
Evap. $(E)$ & 5140 & 5759 & 6465 & $+12 \%$ \\
$P-E$ & 11763 & 12750 & 15638 & $+23 \%$ \\
Transp. $(T)$ & 11322 & 12033 & 14669 & $+22 \%$ \\
$(P-E)-T$ & 441 & 717 & 969 & \\
\hline
\end{tabular}

Note: Transport indicates the net transport of water vapour across $60^{\circ} \mathrm{S}$.

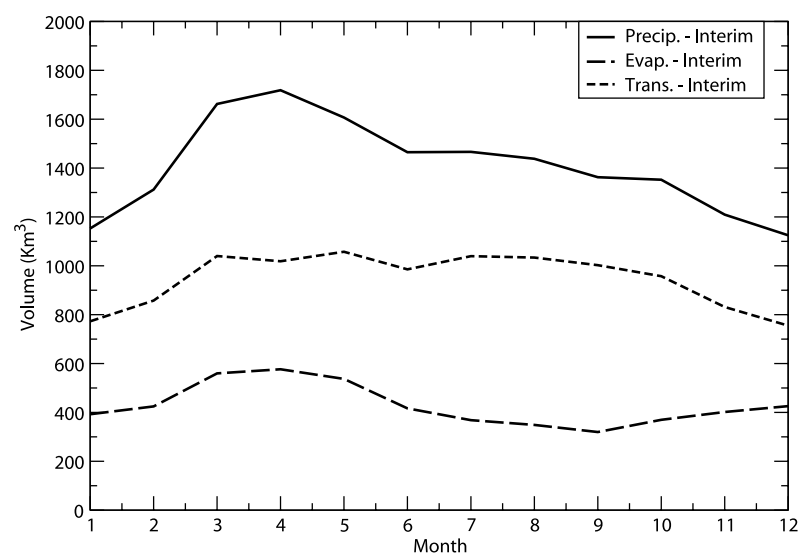

Fig. 5. Same as Fig. 1 but for the southern hemisphere, $60^{\circ} \mathrm{S}$.

larger residuals of the model $(P-E)-T$ is thought to be due to the lower vertical resolution of the model (31 vs. 60 in ERAInterim). The lowest model level is $4 \mathrm{hPa}$ above the surface compared to $1 \mathrm{hPa}$ in the reanalysis. The seasonal cycle of $P, E$ and $T$ is shown in Fig. 8 together with those for ERA-Interim for

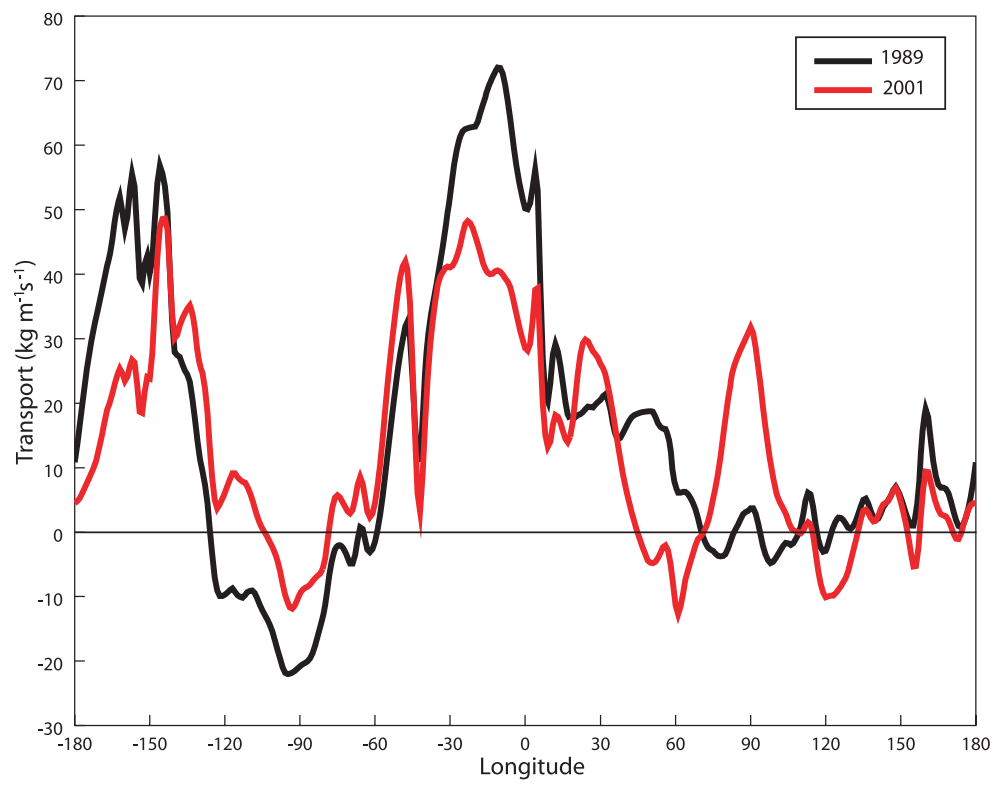

Fig. 4. Annual transport across $600 \mathrm{~N}$ for the years 1989 and 2001, units are $\mathrm{kg} \mathrm{m}^{-1} \mathrm{~s}^{-1}$. 


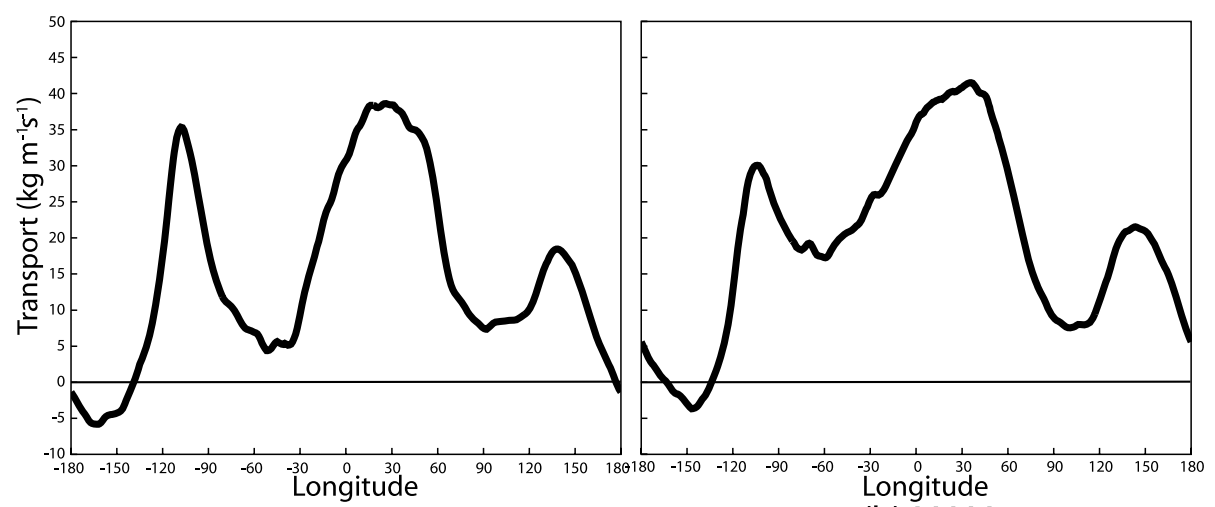

(a) DJF

(b) MAM

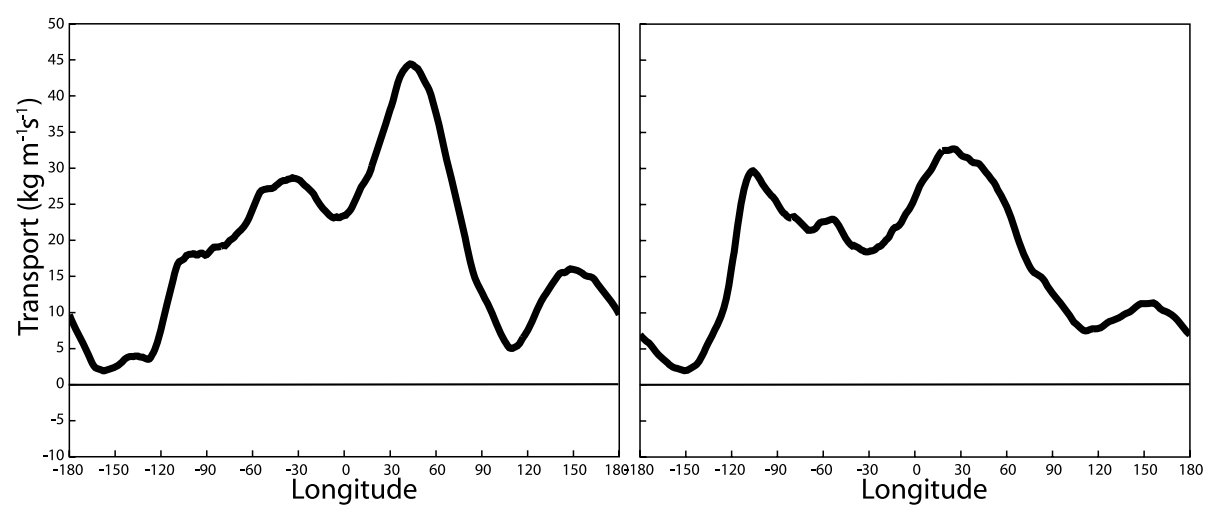

(c) JJA

(d) SON

Fig. 6. Same as Fig. 2 but for the southern hemisphere $60^{\circ} \mathrm{S}$.

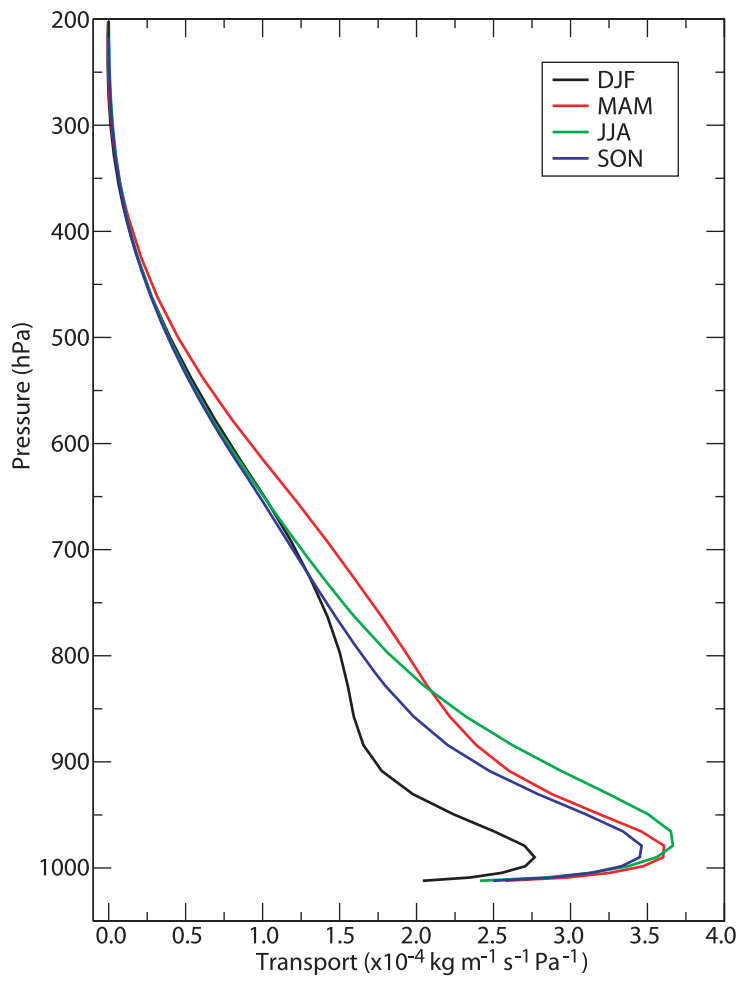

Fig. 7. Same as Fig. 3 but for southern hemisphere, $60^{\circ} \mathrm{S}$. contrast. The $95 \%$ confidence interval is shaded. The transition of the transport to the larger late summer and autumn transport occurs earlier in July in the model run than in ERA-Interim. Otherwise the agreement is quite good. In Fig. 9 the net moisture transport across $60^{\circ} \mathrm{N}$ is shown for both ERA-Interim and the ECHAM5, 20C simulation. The agreement with ERA-Interim is generally very good showing the regions of maximum net transport in the central Pacific and between Iceland and Norway. However, two areas of disagreement stand out. The transport in the 20C simulation is underestimated around $20^{\circ} \mathrm{W}$ in winter (Fig. 9a) and overestimated in the central Pacific in the summer (Fig. 9c). The cause of the underestimation in winter is likely related to a systematic error of the model in preferentially letting cyclones move eastward over Scandinavia instead of the typical split of the jet stream in the area with some cyclones moving into the Arctic region while others following a more south easterly track. The model error can also be seen as an underestimation in simulating wintertime atmospheric blocking (Tyrlis and Hoskins, 2008). However, as can be seen from Fig. 9 the inter-annual variability is very high. For the other seasons in this region there is also good agreement of the moisture transport between ERA-Interim and the 20C simulation. This is also the case during the spring when atmospheric blocking in the Atlantic has a maximum (Rex, 1950). 


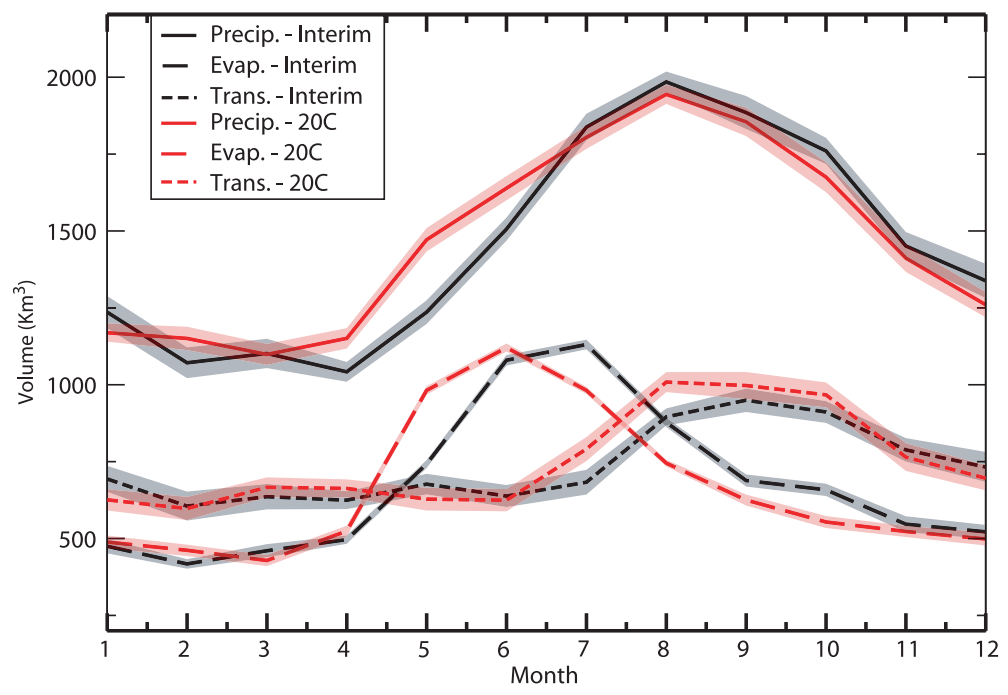

Fig. 8. Same as Fig. 1 but including $P, E$ and $T$ for the ECHAM5, 20C. Shading indicates the $95 \%$ confidence regions based on the standard error.
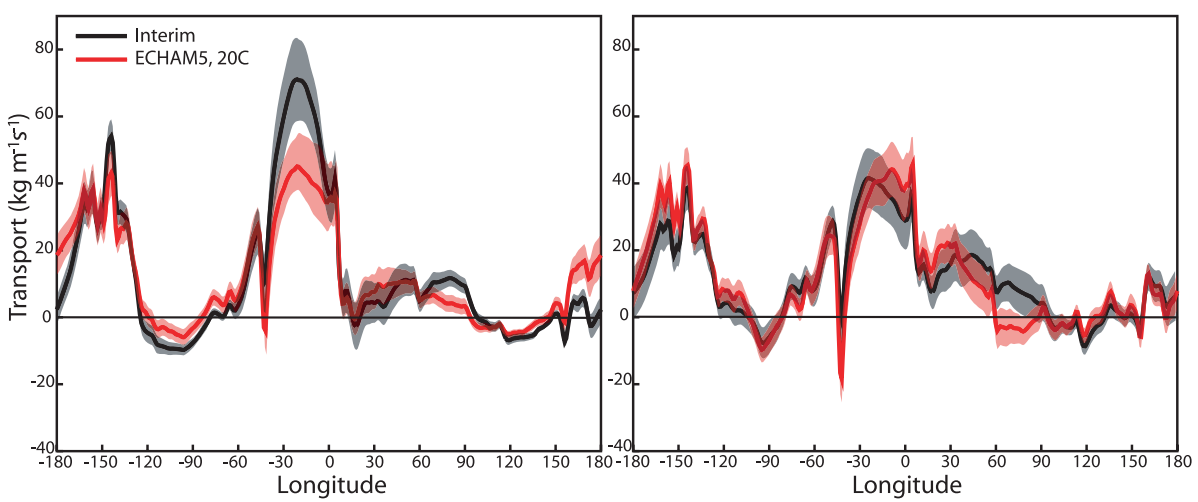

(a) DJF

(b) MAM
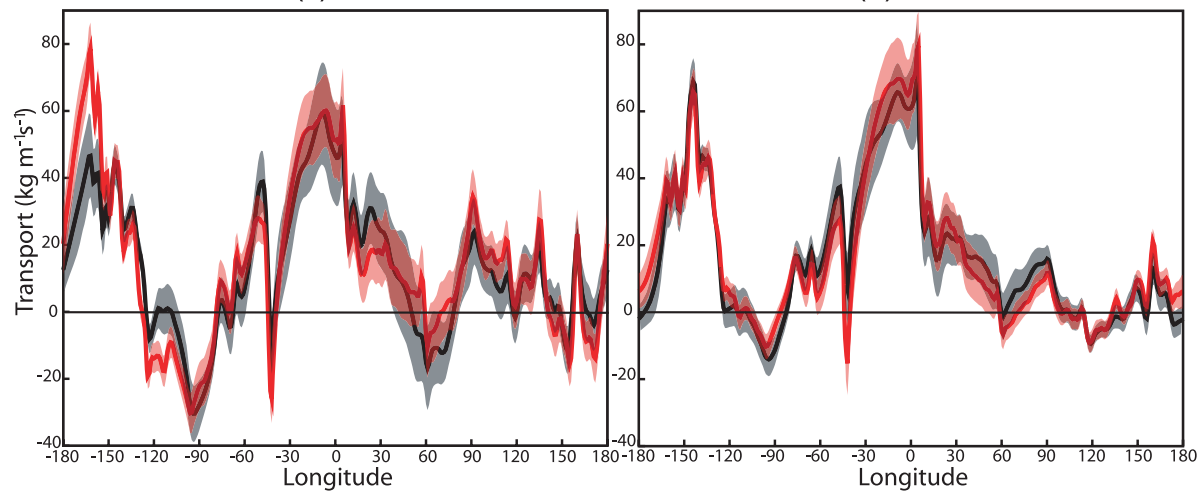

(c) JJA

(d) SON

Fig. 9. Mean transport across $60^{\circ} \mathrm{N}$ for ERA-Interim (black) and ECHAM5, 20C (red), for (a) Winter (DJF), (b) Spring (MAM), (c) Summer (JJA) and (d) Autumn (SON). Units are $\mathrm{kg} \mathrm{m}^{-1} \mathrm{~s}^{-1}$. Shading indicates the $95 \%$ confidence region based on the standard error.

However, although this systematic error occurs in this particular simulation of the ECHAM5 model, which used the 2nd ensemble member of the ECHAM5 A1B simulations for IPCC AR4 for the boundary conditions, the other two ensemble members show a less zonal distribution of the storm tracks and hence if used as boundary conditions in time slice integrations may show less of this type of error. This further highlights the need for longer integrations or ensembles.

In the $21 \mathrm{C}$ experiment describing the climatology for the years 2069-2100 there is a considerable enhancement of the atmospheric hydrological cycle as summarised in Table 1. The net moisture transport for example increases by $29 \%$ com- 


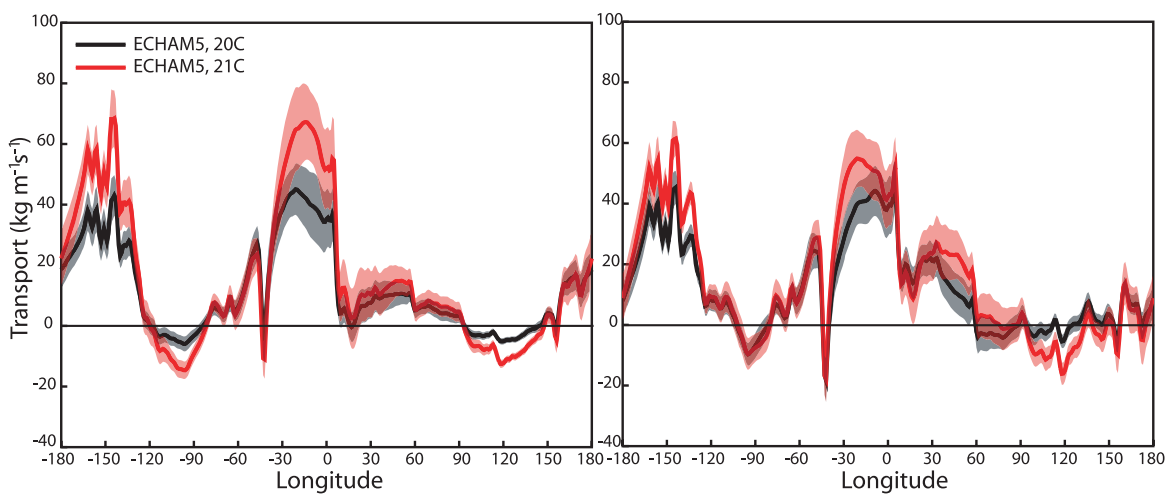

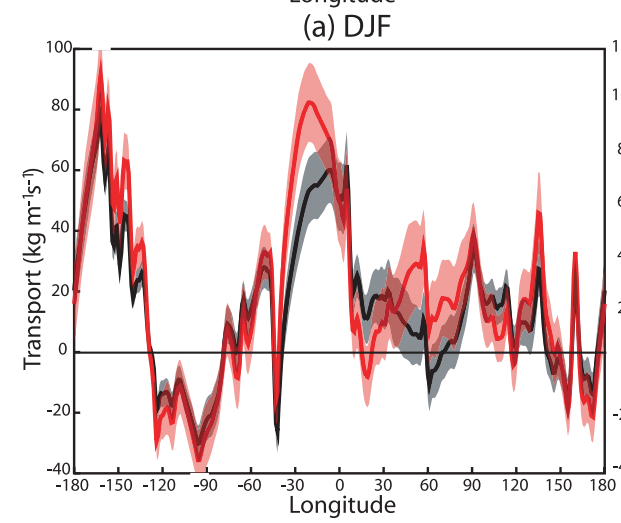

(c) JJA

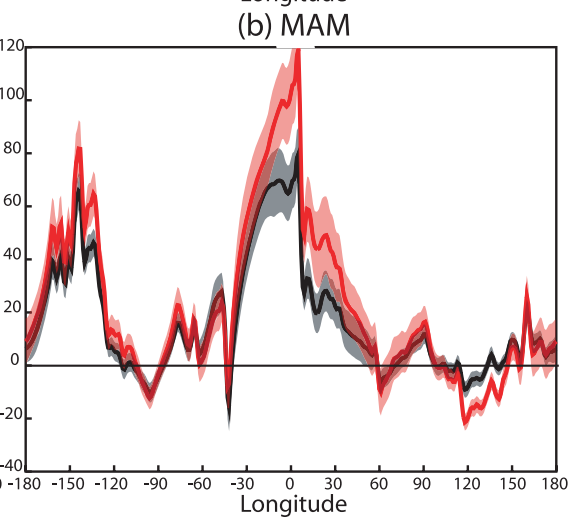

(d) SON

Fig. 10. Same as Fig. 9 except for ECHAM5 20C (black) and ECHAM5 21C (red). Shading indicates the 95\% confidence region based on the standard error.

pared to 20C. The transport across $60^{\circ} \mathrm{N}$ is shown in Fig. 10 . This shows that to a first approximation the pattern of transport is similar to $20 \mathrm{C}$ with the areas of dominant transport between Norway and Iceland and in the Eastern Pacific. The maximum amplitudes are larger and broadly proportional to the increase in moisture. This can be noticed also at longitudes where there is a net outflow of moisture. The strong autumn transport increase between $30^{\circ} \mathrm{W}$ and $10^{\circ} \mathrm{E}$ is striking. This suggests an increased preference for a northward net moisture flux over Scandinavia and the Norwegian Sea into the Arctic.

The annual mean vertical profile of moisture transport for the ECHAM5 20C and 21C are contrasted with ERA-Interim in Fig. 11, this shows results that are consistent with the results so far discussed in that the $20 \mathrm{C}$ experiment has a very similar transport to ERA-Interim. As can be seen from Table 1 the transport is much larger in $21 \mathrm{C}$ than $20 \mathrm{C}$ although the shapes of the vertical distributions are similar with the largest transport occurring at around $975 \mathrm{hPa}$ for all three data sets.

We have also investigated the annual trends for $20 \mathrm{C}$ and $21 \mathrm{C}$, these are shown in Fig. 12. There are large differences between $20 \mathrm{C}$ and $21 \mathrm{C}$ and these differences are clearly significant. However, as can be seen from individual periods there are no indications of any significant trends (errors quoted are $95 \%$ confidence intervals), suggesting that the 30-year period is too short in view of the large inter-annual variation.

\section{The Antarctic region}

The model simulation for 20C agrees less well with ERA-Interim in the Antarctic region than was the case in the Arctic. The water cycle is more intense and $P, E$ and $T$ terms are $9 \%, 12 \%$ and $6 \%$ larger, respectively (Table 2). Whether this is a model error or a bias with respect to the ERA-Interim reanalyses cannot be determined, but we might suggest, in view of the agreement in the Northern Hemisphere that the somewhat poorer observing network at high latitudes of the Southern Hemisphere might imply a negative bias in the water vapour transport by ERA-Interim. On the other hand inter-comparing the recent high resolution reanalyses, including ERA-Interim, for extra-tropical cyclones and the storm tracks suggests that they compare very well in the $\mathrm{NH}$ and also almost as well in the SH (Hodges et al., 2011). This is different from the older reanalyses (Hodges et al, 2003, 2004; Wang et al., 2006). Hence, the problem may well be one of error in the model. There is some indication of this for the ECHAM5 model in the SH from the study of Bengtsson et al. (2006), where there appears to be too much activity through the Australian/New Zealand region again perhaps indicative of blocking being to weak and a deficiency in the representation of the split jet (Inatsu and Hoskins, 2004), there are also deficiencies in the cyclogenesis in lee of the Andies. Each of these deficiencies may have an impact on the transport of moisture in 


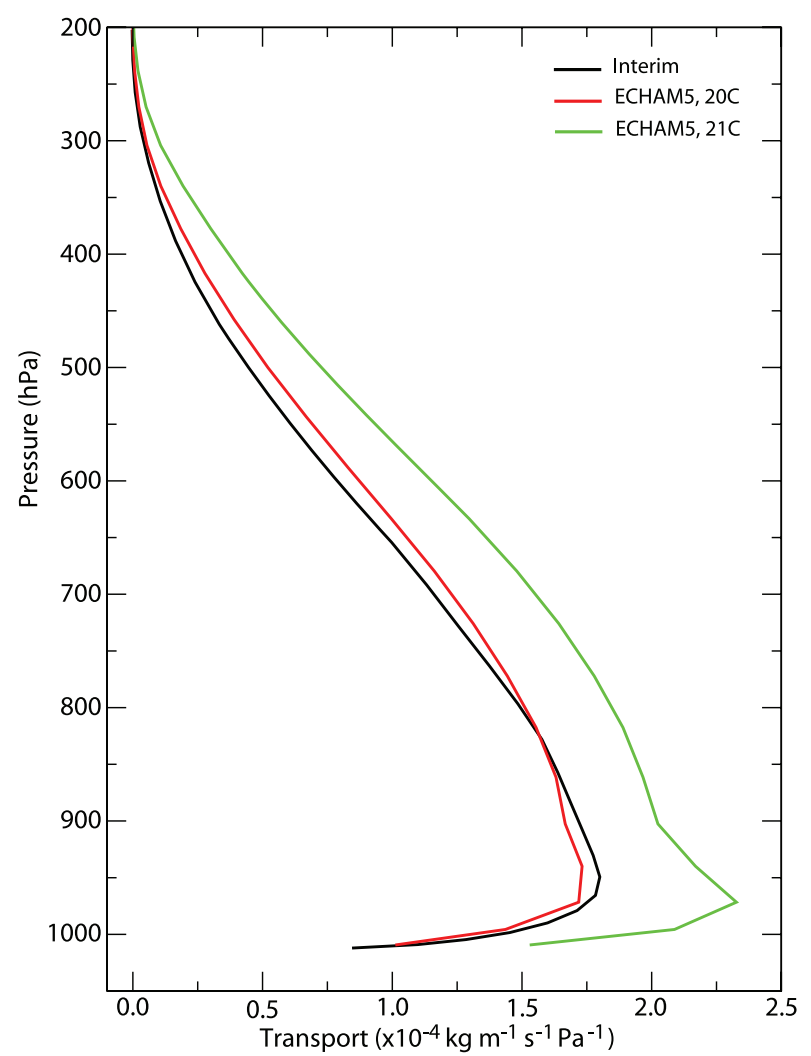

Fig. 11. Annual mean vertical profile of the moisture transport across the $60^{\circ} \mathrm{N}$ parallel, for ERA-Interim (black), ECHAM5, 20C (red) and ECHAM5, 21C (green). Units are $\times 10^{-4} \mathrm{~kg} \mathrm{~m}^{-1} \mathrm{~s}^{-1} \mathrm{~Pa}^{-1}$.

the Antarctic region. It is unclear if these problems also occur for other climate models.

The model simulation of the moisture transport agree less well with ERA-Interim than in the $\mathrm{NH}$ for almost all seasons in particular in the western hemisphere, as shown in Fig. 13. This could be due to sampling problems as the storm tracks in the $\mathrm{SH}$ are less locked in by the distribution of land and ocean as is the case in the $\mathrm{NH}$ and the storm tracks over the almost continuous Southern Ocean around Antarctica are less constrained in the east-west direction.

In the $21 \mathrm{C}$ experiment there is, as for the Arctic, a considerable enhancement of the atmospheric hydrological cycle as shown in Table 2. The net water vapour transport, for example, is $22 \%$ higher compared to $20 \mathrm{C}$. The net moisture transport across $60^{\circ} \mathrm{S}$ is shown in Fig. 13. The pattern is similar to 20C except a tendency for a more dominant transport in the region $60^{\circ} \mathrm{W}$ to $60^{\circ} \mathrm{E}$ and this mainly during the austral winter and spring seasons.

We have investigated the annual trends for $20 \mathrm{C}$ and $21 \mathrm{C}$, which are shown in Fig. 14 for $P, E$ and $T$. There are large differences between $20 \mathrm{C}$ and $21 \mathrm{C}$. There is an indication of a positive trend for precipitation and the horizontal transport at 21C.

\section{Discussion}

For the Arctic the high-resolution atmospheric model simulates the transport of water vapour across $60^{\circ} \mathrm{N}$ in close agreement with the ERA-Interim reanalyses. This is the case for both the annual mean as well as the inter-annual variance. The mean monthly net transport is within $10 \%$ of the reanalyses, except for July and August when the model result is $14 \%$ and $12 \%$ higher, respectively. These deviations are likely due to sampling problems. The same is the case for precipitation and evaporation. There is a rapid transition in Arctic evaporation from April through June when it more than doubles. This appears to occur earlier in the model with the effect that the evaporation in the model calculation is some $32 \%$ higher in May with a reverse result in July. This might indicate an earlier snowmelt in the model than in the reanalyses.

The net transport of moisture across $60^{\circ} \mathrm{N}$ is mainly concentrated to two regions. The first region is between $20^{\circ} \mathrm{W}$ and $10^{\circ} \mathrm{E}$ over the Norwegian Sea and Scandinavia, or at the end of the Atlantic storm tracks. This is where the extra-tropical storms are often becoming quasi-stationary resulting in mild and humid air being transported into the Arctic on the eastern flank. Another area is found at the end of the Pacific storm track between $130^{\circ} \mathrm{W}$ and $160^{\circ} \mathrm{W}$. The transports are largest in the autumn because of the comparatively high level of moisture that will more than compensate for the stronger winds during winter. There is a considerable inter-annual variability as can be seen in the comparison in moisture transport between the years 1989 and 2001. In spite of a minor warming of the lower troposphere of $\sim 0.13^{\circ} \mathrm{C} /$ decade in the global mean between 1989 and 2009 (ERA-Interim) it is not possible to identify any significant trend in the moisture transport because of the large inter-annual variations and the relative shortness of the period. There is a minimum in 1992 following the Pinatubo eruption but will require an ensemble experimentation to clarify whether this is a robust signal or just a minimum happening by chance.

The results for Antarctic are less favourable and, for example, $P-E$ in the model is some $8 \%$ stronger in the model run compared to ERA-Interim. This could indicate a bias in ERAInterim related to data deficiencies. However, the reanalyses are based on an NWP-model that has improved dramatically in the $\mathrm{SH}$ in recent years, and are now almost as good as in the NH. In addition, studies that compare the storm tracks in the $\mathrm{SH}$ using the latest high resolution reanalyses, including ERA-Interim, suggest that the SH storm tracks inter-compare almost as well in the $\mathrm{SH}$ as in the $\mathrm{NH}$ (Hodges et al., 2011). The results by Nicholas and Bromwich (2011) indicate that the ERA-Interim performs quite satisfactory in the Antarctic region. A systematic model error is also suggested from other modelling studies, (Catto et al., 2010) showing similar storm track biases as in the model used here. Part of the differences might be sampling problems as the Southern Hemisphere storm tracks are less confined than for the Northern Hemisphere. Others could be diffi- 

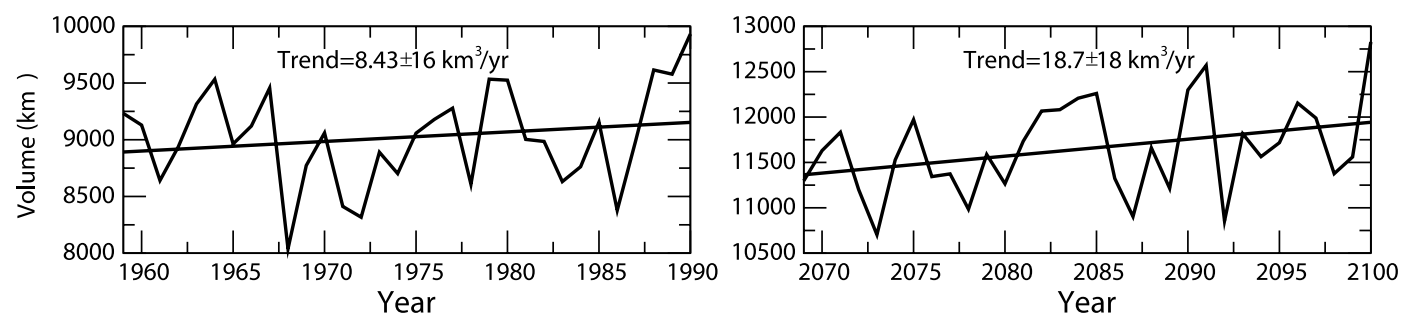

(a) 20C Transport

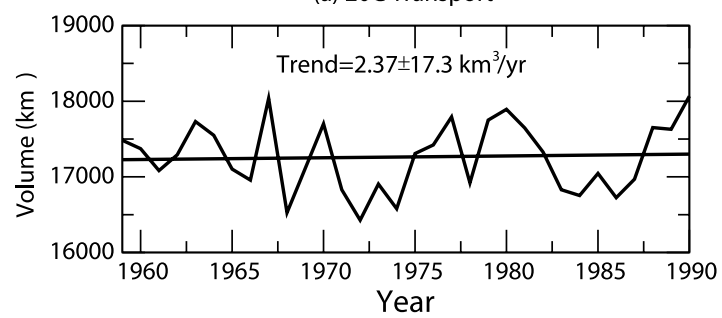

(b) $21 \mathrm{C}$ Transport

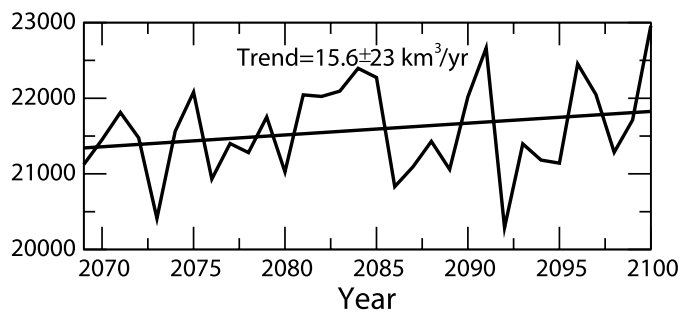

(c) 20C Precip

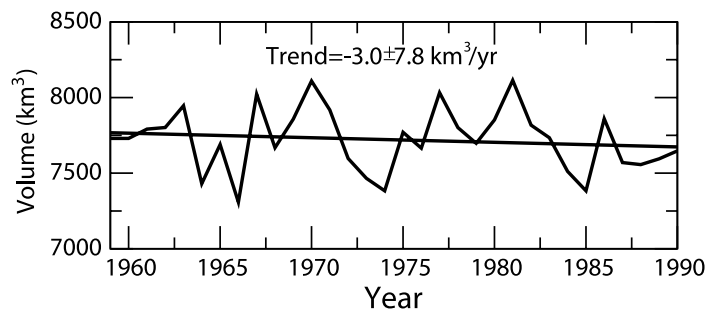

(d) 21 C Precip

(e) 20 C Evap.

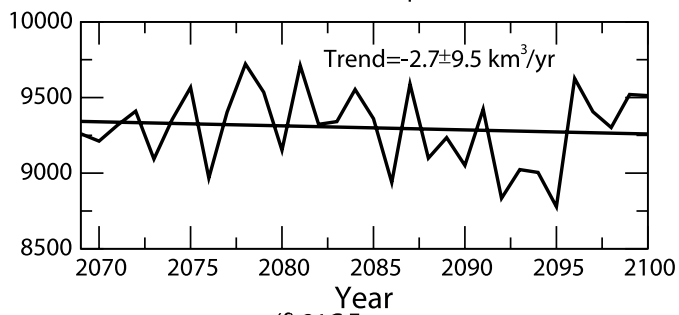

(f) 21C Evap.

Fig. 12. Time series and trends for $T, P$ and $E$, respectively for the ECHAM5, 20C and $21 \mathrm{C}$ experiments for the northern hemisphere, $60^{\circ} \mathrm{N}-90^{\circ} \mathrm{N}$. (a) 20C transport, (b) $21 \mathrm{C}$ transport, (c) $20 \mathrm{C}$ precipitation, (d) $21 \mathrm{C}$ precipitation, (e) 20C evaporation, (f) $21 \mathrm{C}$ evaporation. Units are $\mathrm{km}^{3}$. The $95 \%$ confidence interval of the trend is based on the standard error.

culties in correctly handling the split jet and the associated subtropical and polar storm tracks, which are dominant in the winter period.

The comparison with ERA Interim is primarily to assure that the model is generating meaningful results. We believe this is the case even if there exist principal differences between the model experiment and the calculations from the ERA Interim data in particular for Antarctica. The model calculation is $30 \mathrm{yrs}$, compared to $20 \mathrm{yrs}$ in the reanalysis, and the model study starts in 1959 while the reanalysis starts in 1989. As we do not notice any significant trend in the moisture transport neither in the reanalysis nor in the $20 \mathrm{C}$ experiment at $60^{\circ} \mathrm{N}$ and $60^{\circ} \mathrm{S}$ we do not consider these differences to be of any primary importance. We consider therefore that the inter-comparison with ERA Interim is sufficient for our purpose to assure that the model provides credible results.

There is a significant increase in the transport of moisture across $60^{\circ} \mathrm{N}(+29 \%)$ and $60^{\circ} \mathrm{S}(+22 \%)$ during the $21 \mathrm{C}$ under the assumption of the A1B scenario. This follows closely the $\mathrm{CC}$ relation, however, the increase is proportionally larger than given by Held and Soden (2006). The increase in precipitation is slightly less but follows closely the net transport. There is also an increase in evaporation but less than for the net trans- port. There are hardly any changes in the large-scale circulation except a minor poleward translation in the major storm tracks (see discussion in Bengtsson et al., 2006, 2009). The pattern of transport is essentially unchanged except for the general enhancement including areas of minor net transport out of the Polar Regions. The net transport into the Arctic is dominated by the strong transport in the eastern Pacific and eastern North Atlantic. The increase in the autumn and winter transport in the area between Iceland and Norway stands out. The increased transport of moisture into the Arctic and Antarctic region will contribute to increased accumulation of land ice and glaciers and thus counteract the increase in ablation in summer caused by the higher temperatures. Indications are (Bengtsson et al., 2011 and references therein) nevertheless that the surface mass balance (not including calving of ice) of Greenland is expected to gradually become negative, whilst staying positive for Antarctica well beyond the end of the $21 \mathrm{C}$.

The close agreement in the Arctic between the modelled water cycle and the water cycle inferred from ERA-Interim is very encouraging both for the quality of the ERA-Interim reanalyses and for the ECHAM5 high resolution climate model. The poorer agreement of the results from the Antarctic will require further studies. The experiments support previous studies (Held and 


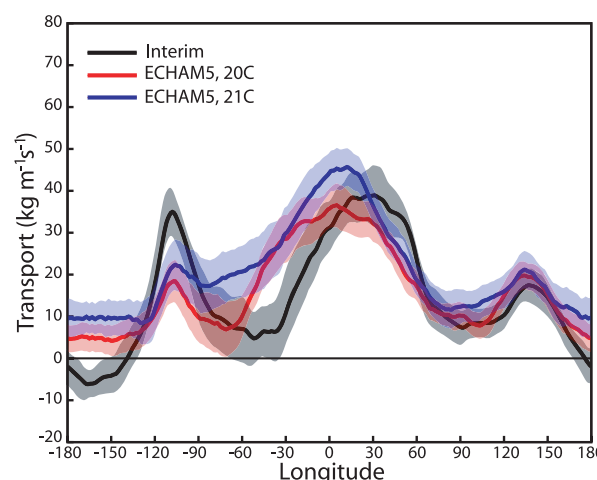

(a) DJF

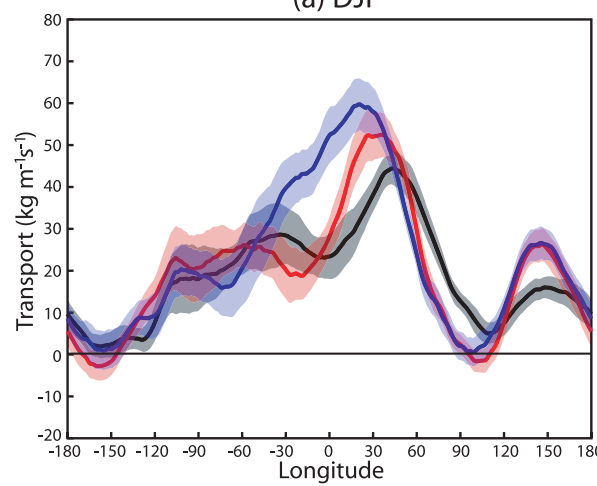

(c) JJA

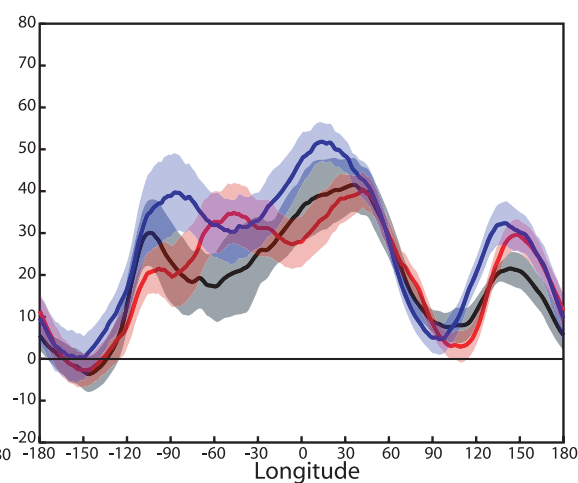

(b) MAM

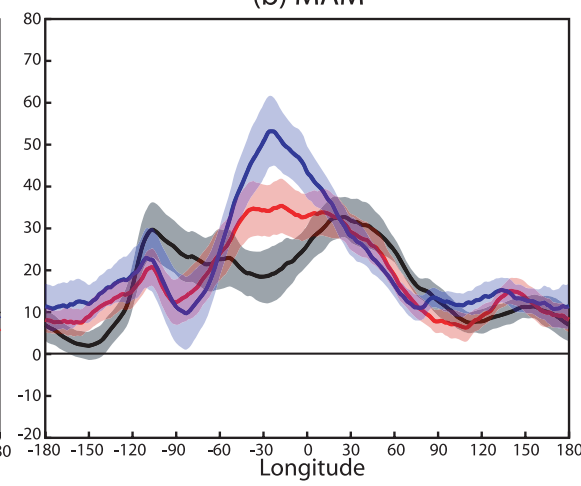

(d) SON

Fig. 13. Mean transport across $60^{\circ} \mathrm{S}$ for ERA-Interim (black) and ECHAM5, 20C (red) and ECHAM5, 21C (green), for (a) Winter (DJF), (b) Spring (MAM), (c) Summer (JJA) and (d) Autumn (SON). Units are $\mathrm{kg} \mathrm{m}^{-1} \mathrm{~s}^{-1}$. Shading indicates the $95 \%$ confidence region based on the standard error.

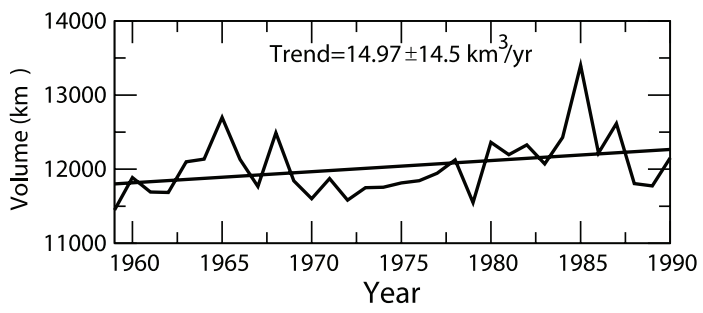

(a) 20C Transport

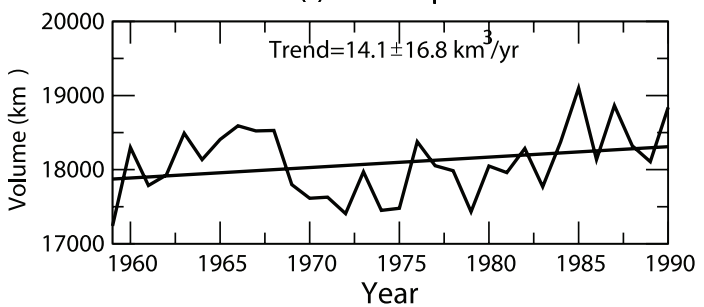

(c) 20 C Precip.

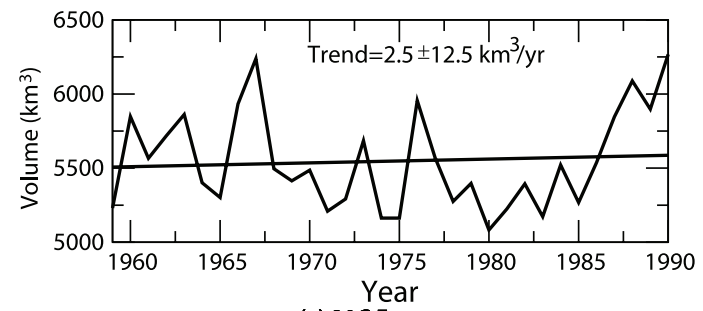

(e) 20 C Evap.

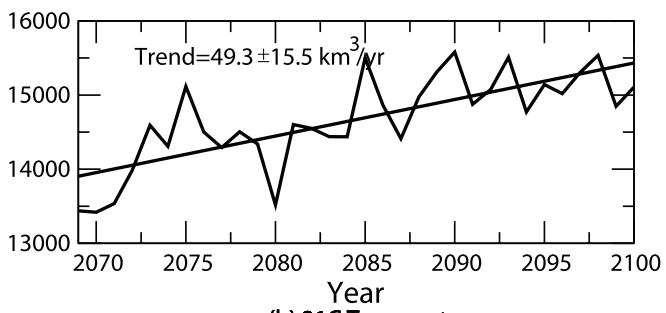

(b) 21C Transport

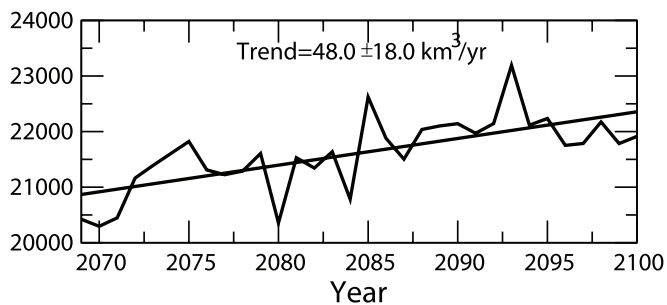

(d) 21C Precip.

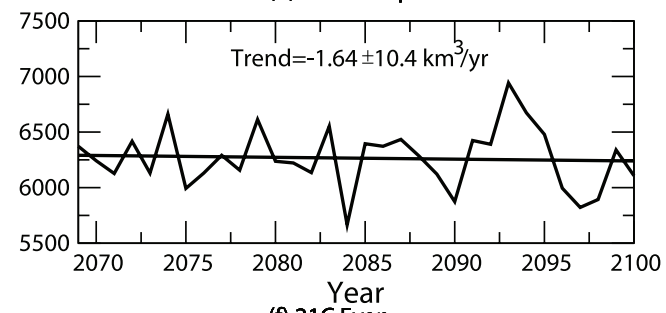

(f) 21C Evap.

Fig. 14. Same as Fig. 12 but for the southern hemisphere. 
Table 3. Annual mean change in water vapour transport in percent across $60^{\circ} \mathrm{N}$ and $60^{\circ} \mathrm{S}$ for 20C (1959-1990) and 21C (2069-2100) for seven different models taking part in the IPCC Assessment 4 for the A1B scenario.

\begin{tabular}{lccc}
\hline Model & $\begin{array}{c}\text { 21C-20C } \\
\text { Arctic (\%) }\end{array}$ & $\begin{array}{c}\text { 21C-20C } \\
\text { Antarctic (\%) }\end{array}$ & dT (global) $\left({ }^{\circ} \mathrm{K}\right)$ \\
\hline ECHAM5(3) & 25 & 22 & 3.2 \\
NCAR(5) & $20(24)$ & $23(27)$ & 2.7 \\
UKMO(1) & $29(32)$ & $20(22)$ & 2.9 \\
IPSL(1) & $27(27)$ & $31(31)$ & 3.2 \\
MRI(5) & $16(21)$ & $18(24)$ & 2.4 \\
CSIRO(1) & $22(23)$ & $24(26)$ & 3.0 \\
CNMR(1) & $23(28)$ & $18(21)$ & 2.7 \\
Mean & 26 & 25 & 3.2 \\
\hline
\end{tabular}

Notes: Values in parenthesis have been modified using the Clausius-Clapeyron relation and the change in global mean temperature between $20 \mathrm{C}$ and $21 \mathrm{C}$ relative to ECHAM5. For some of the models the mean of different experiments has been used.

Soden, 2006; Kattsov et al., 2007) that showed considerable enhancement of the atmospheric water cycle in the two Polar Regions. We have also calculated the change in $P-E$ for the two polar regions from a number of models used in the 4th IPCC assessment, and data available in CMIP3, for the A1B scenario. These are lower resolution models then the T213 resolution used in the analysis in the rest of the paper, but the $P-E$ calculations have been performed in the same way, namely that the average change in $P-E$ between the two periods, 1959-1990 (20C) and 2069-2100 (21C) is calculated. The results are summarized in Table 3, where we have also normalized the values with the global mean temperature change making use of the $\mathrm{CC}$ relation. This shows that the results shown above for the high-resolution model are consistent with these and with the CC relation as discussed.

The increasing trend can presently not be identified from the 21-year long ERA-Interim data set and as suggested from the modelling results, will require an enhanced record of data. Examining some of the longer reanalyses, in particular the latest high resolution reanalysis such as the NCEP-CFSR (Saha et al., 2010), available from 1979 may help and provide further confidence in the results from ERA-Interim. However, a continuous warming of the climate system is expected to lead to a rapid increase in the transport of water vapour into the Polar Regions. This will play an important role in assessing the future mass balance of polar glaciers and land ice.

Finally, the quality of the ERA-Interim reanalysis and other new and future reanalyses is likely to make it possible to assess the energy balance of the Polar Regions more accurately and to be able to compare the balance between energy transports into the regions with the radiative losses as measured from space. Such studies are now underway.

\section{Acknowledgment}

The authors would like to thank ECMWF for making the ERA-Interim data available. The ECHAM5 simulations were performed at HLRN (Norddeutscher Verbund für Hoch und Höchstleistungsrechnen).

\section{References}

Bengtsson, L., Hagemann, S. and Hodges, K. I. 2004. Can climate trends be calculated from reanalysis data? JGR-Atmos. 109, D11111, doi:10.1029/2004JD004536.

Bengtsson, L., Hodges, K. I. and Roeckner, E. 2006. Storm Tracks and Climate Change. J. Climate V19, 3518-3543.

Bengtsson, L., Hodges, K. I., Esch, M., Keenlyside, N., Kornblueh, L., and co-authors. 2007. How may tropical cyclones change in a warmer climate? Tellus V59A, 539-561.

Bengtsson, L., Hodges, K. I. and Keenlyside, N. 2009. Will Extratropical Storms Intensify in a Warmer Climate? J. Climate 22, 22762301.

Bengtsson, L., Koumoutsaris S. and Hodges, K. 2011. Large-scale surface mass balance of ice sheets from comprehensive atmospheric model. Surv. Geophys. in press, doi:10.1007/s10712-011-9120-8.

Bromwich, D. H., Wang, S.-H. and Monaghan, A. J. 2002. ERA-40 representation of the Arctic atmospheric moisture budget. In ERA40 Project Report Series, \#3. ECMWF Workshop on Reanalysis, 287-298.

Bromwich, D. H., Fogt, R. L., Hodges, K. I. and Walsh, J. E. 2007. A tropospheric assessment of the ERA-40, NCEP, and JRA-25 global reanalyses in the polar regions. J. Geophys. Res. 112, doi: 10.1029/2006JD007859.

Bromwich, D. H. and Wang, S-H. 2008. A review of the temporal and spatial variability of Arctic and Antarctic atmospheric circulations based upon ERA-40. Dyn. Atmos. Oceans 44, 213-243.

Catto, J. L., Shaffrey, L. C. and Hodges, K. I. 2010. Northern Hemisphere Extratropical Cyclones in a Warming Climate in the HiGEM High Resolution Climate Model. J. Climate, doi:10.1175/2011JCLI4181.1.

Cullather, R. I., Bromwich, D. H. and Serreze, M. C. 2000. The atmospheric hydrologic cycle over the Arctic basin from reanalyses. Part I. comparison with observations and previous studies. J. Climate 13, 923-937.

Dee, D. P. and Uppala, S. 2009. Variational bias correction of satellite radiance data in the ERA-Interim reanalysis. Q. J. Royal Met. Soc. 135, 1830-1841.

Dee, D. P., Uppala, S. M., Simmons, A. J., Berrisford, P., Poli, P. and co-authors. 2011. The ERA-Interim reanalysis: configuration and performance of the data assimilation system. Quart. J. R. Meteorol. Soc. 137, 553-597.

Genthon, C. and Krinner, G. 1998. Convergence and disposal of energy and moisture on the Antarctic polar cap from ECMWF reanalyses and forecasts. J. Climate 11, 1703-1716.

Giovinetto, M. B., Bromwich, D. H. and Wendler, G. 1992. Atmospheric net transport of water vapor and latent heat across 70S. J. Geophys. Res. 97, 917-930.

Giovinetto, M. B., Yamazaki, K., Wendler, G. and Bromwich, D. H. 1997. Atmospheric net transport of water vapor and latent heat across $60^{\circ}$ S. J. Geophys. Res. 102(D10), 11171-11179. 
Held, I. M. and Soden, B. J. 2006. Robust responses of the hydrological cycle to global warming. J. Climate 19, 5686-5699.

Hodges, K. I., Hoskins, B. J., Boyle, J. and Thorncroft, C. 2003. A comparison of recent reanalysis datasets using objective feature tracking: storm tracks and tropical easterly waves. Mon. Wea. Rev. 131, 2012-2037.

Hodges, K. I., Hoskins, B. J., Boyle, J. and Thorncroft,C. 2004. Corrigendum: a comparison of recent reanalysis datasets using objective feature tracking: storm tracks and tropical easterly waves. Mon. Wea. Rev. 132, 1325-1327.

Hoskins, B. J. and Hodges, K. I. 2005. A new perspective on Sourthern Hemisphere storm tracks. J. Climate 18, 4108-4129.

Hodges, K. I., Lee, R. W. and Bengtsson, L. 2011. Comparison of Extra-Tropical Cyclones in Recent Re-analyses; ERANTERIM, NASA-MERRA, NCEP-CFSR and JRA25. J. Climate, doi:10.1175/2011JCLI4097.1.

Inatsu, M. and Hoskins, B. J. 2004: The zonal asymmetry of the Southern Hemisphere winter storm track. J. Climate 17, 4882-4892.

Jakobson, E. and Vihma, T. 2010, Atmospheric moisture budget in the Arctic based on the ERA-40 reanalysis. Int. J. Climatol. 30, 2175-2194. doi: 10.1002/joc.2039.

Kattsov, V. M., Walsh, J. E., Chapman, W. L., Govorkova, V. A., Pavlova, T. V., and co-authors. 2007. Simulation and projection of arctic freshwater budget components by the IPCC AR4 global climate models. J. Hydrometeor. 8, 571-589.

Lettau, B. 1969. The transport of moisture into the Antarctic interior. Tellus 21, 331-340.

Nakicenovic, N., Alcamo, J., Davies, G., DeVries, B., Fenhann, J. and co-authors. 2000. Special Report on Emissions Scenarios. Cambridge University Press, 599 pp.

Nicholas, J. P. and Bromwich, D. H. 2011. Precipitation changes in high southern latitudes from global reanalyses: a cautionary tale. Surv. Geophys., in press, doi: 10.1007/s10712-011-9114-6.

Pierrehumbert, R. T., Brogniez, H. and Roca, R. 2007. On the relative humidity of the Earth's atmosphere. In: The Global Circulation of the Atmosphere, (eds. Schneider, T. and Sobel, A. H.), Princeton University Press, Princeton, NJ, 143-185.

Rawlins, M. A., Steele, M., Holland, M. M., Adam, J. C., Cherry, J. E. and co-authors. 2010. Analysis of the Arctic System for Freshwater Cycle Intensification: Observations and Expectations. J. Climate 23, 5715-5737.

Rex, D. F. 1950. Blocking action in the middle troposphere and its effect upon regional climate. II. The climatology of blocking action. Tellus 2, 275-301.

Roeckner, E., Brokopf, R., Esch, M., Giorgetta, M., Hagemann, S., and co-authors. 2006. Sensitivity of simulated climate to horizontal and vertical resolution in the ECHAM5 atmosphere model, J. Climate 19, 3771-3791.

Rogers, A. N., Bromwich, D. H., Sinclair, E. N. and Cullather, R. I. 2001. The atmospheric hydrologic cycle over the Arctic Basin from reanalyses. Part II: interannual variability. J. Climate 14, 24142429.

Saha, S., Moorthi, S., Pan, H.-L., Wang, J., Nadiga, S. and co-authors. 2010. The NCEP climate forecast system reanalyses, Bull. Amer. Met. Soc. 91, 1015-1057.

Serreze, M. C., Bromwich, D. H., Clark, M. P., Etringer, A. J., Zhang, T. and co-authors. 2003. The large-scale hydro-climatology of the terrestrial Arctic drainage. J. Geophys. Res. 108, 8160, doi: 10.1029/2001JD000919.

Serreze, M. C., Barrett, A. P., Slater, A. G., Woodgate, R. A., Aagaard, K. and co-authors. 2006. The large-scale freshwater cycle of the Arctic. J. Geophys. Res. 111, C11010, doi:10.1029/2005JC003424.

Simmons, A., Uppala, S., Dee, D. and Kobayashi, S. 2007. ERA-Interim: New ECMWF reanalysis products from 1989 onwards. ECMWF Newsletter No. 110, 25-25.

Takahashi, K. 2009. Radiative constraints on the hydrological cycle in an idealized radiative-convective equilibrium model. J. Atmos. Sci 66, 77-91.

Tietäväinen, H. and Vihma, T. 2008. Atmospheric moisture budget over Antarctica and the Southern Ocean based on the ERA-40 reanalysis. Int. J. Climatol. 28, 1977-1995.

Tyrlis, E. and Hoskins, B. J. 2008. Aspects of a Northern Hemisphere atmospheric blocking climatology. J. Atmos. Sci. 65, 1638-1652.

Wang, X. L., Swail, V. R. and Zwiers, F. W. 2006. Climatology and changes of extratropical cyclone activity: comparison of ERA-40 with NCEP-NCAR reanalysis for 1958-2001. J. Clim. 19, 3145-3166. 